\title{
Balanced Salt Solution Versus Normal Saline in Resuscitation of Pediatric Sepsis: A Randomized, Controlled Trial
}

\author{
Sirawut Trepatchayakorn ${ }^{1}$ (D) $\cdot$ Manee Sakunpunphuk $^{2} \cdot$ Rujipat Samransamruajkit $^{1}$
}

Received: 7 March 2021 / Accepted: 10 May 2021 / Published online: 10 June 2021

(C) Dr. K C Chaudhuri Foundation 2021

\begin{abstract}
Current evidences in resuscitation of adult sepsis have pointed to the importance of types of crystalloid fluid-related complications on resuscitation outcomes, but evidences are lacking in pediatric populations. In this study, the authors aimed to compare outcomes of pediatric sepsis resuscitation with different types of crystalloid. They randomly assigned pediatric sepsis patients requiring fluid bolus into three groups to receive either normal saline solution (NSS), Ringer lactate solution (RLS), or Sterofundin as fluid bolus therapy. Forty-two patients were included in the study. Median age was 29 mo and, weight $13 \mathrm{~kg}$. After fluid bolus, the complications were not different among groups. However, in the RLS group, the patients who received large dose of the fluid showed significant reduction in urinary neutrophil gelatinase-associated lipocalin (uNGAL) level. It is concluded that fluid bolus therapy with different types of crystalloid solution did not result in different outcomes but large dose of RLS was associated with greater reduction of UNGAL level, compared to other fluids.

Trial Registration: Thai Clinical Trial Registry (TCTR) identification number TCTR20170605001 (retrospectively registered on 1st June 2017). https://www.clinicaltrials.in.th/index.php?tp=regtrials\&menu=trialsearch\&smenu=fulltext\&task20= search\&task2=view $1 \& \mathrm{id}=2576$
\end{abstract}

Keywords Pediatric sepsis $\cdot$ Fluid resuscitation $\cdot$ Fluid bolus $\cdot$ Balanced salt solution

\section{Introduction}

Pediatric sepsis is a leading cause of pediatric intensive care unit (PICU) admissions and mortality. Fluid resuscitation is still an important initial step of treatment. In adult populations, there is a growing body of evidence that shows that balanced salt solution may have superior benefits as compared to unbalanced normal saline in resuscitation of both medical and surgical patients, especially when used in large amount. However, direct evidence in pediatric sepsis populations is scant. The present study aimed to report evidence for the use of balanced salt solution in pediatric populations with sepsis in comparison to normal saline. The primary objective of the

Sirawut Trepatchayakorn

sirawut.t@ chula.ac.th

1 Division of Pediatric Critical Care, Department of Pediatrics, Faculty of Medicine, Chulalongkorn University, 1873 Rama IV Rd, Pathum Wan, Bangkok 10330, Thailand

2 Department of Nursing, King Chulalongkorn Memorial Hospital, Bangkok, Thailand study was to compare acid-base status after fluid bolus therapy with different types of crystalloid fluid. The secondary objective was to compare other PICU outcomes.

\section{Material and Methods}

The study included pediatric patients admitted to King Chulalongkorn Memorial Hospital, who were diagnosed with sepsis and required fluid resuscitation. This study was conducted from November 2016 to November 2019 after intensive review from the Institution Review Board, Faculty of Medicine, Chulalongkorn University, Bankok, Thailand. Informed consent was obtained from parents before randomization. After randomization, patients were divided into three groups to receive study fluid bolus [normal saline solution (NSS), Ringer lactate solution (RLS), or Sterofundin] in 10 $15 \mathrm{~min}$ as resuscitation. Data from initial, $2 \mathrm{~h}, 6 \mathrm{~h}$, and $24 \mathrm{~h}$ after fluid bolus were collected. Urine sample immediately after randomization and at $2 \mathrm{~h}$ after resuscitation was collected for urinary neutrophil gelatinase-associated lipocalin (UNGAL) analysis [1-6]. All data were analyzed using SPSS version 22. 
Patients whose informed consent could not be obtained, had pre-existing renal or liver impairment, were diagnosed as end-stage disease, or had multiple organ dysfunction syndrome before randomization were excluded.

\section{Result}

During the study period, a total of 42 pediatric septic shock patients were included in the study; $57.1 \%$ were males and $42.9 \%$ were females. Median age of participants was 29 mo, weight $13 \mathrm{~kg}$, Pediatric Logistic Organ Dysfunction II (PELODS-II) score 5 points, Pediatric Risk of Mortality III (PRISM-III) score 4 points and, maximal vasopressor-inotropic score (VIS) 10 points. Median time from diagnosis to antibiotics was $60 \mathrm{~min}$. Median dose of fluid was $30 \mathrm{~mL} / \mathrm{kg}$. No difference was found among the three groups regarding arterial $\mathrm{pH}$, base excess, serum lactate, central venous saturation $\left(\mathrm{ScvO}_{2}\right)$, lactate clearance, or base excess change over time.

Table 1 Outcomes for participants who received fluid bolus $\geq 30 \mathrm{~mL} / \mathrm{kg}$ (median, $\mathrm{P}_{25-75}$ )

\begin{tabular}{|c|c|c|c|c|}
\hline & $\begin{array}{l}\text { NSS } \\
\text { group }\end{array}$ & $\begin{array}{l}\text { RLS } \\
\text { group }\end{array}$ & $\begin{array}{l}\text { Sterofundin } \\
\text { group }\end{array}$ & $p$ value \\
\hline \multicolumn{5}{|l|}{ Acid-base status outcomes } \\
\hline \multicolumn{5}{|l|}{ Serum lactate level (mmol/L) } \\
\hline • $\mathrm{T}_{0}$ & $2(1.2-3)$ & $4.9(1.5-8.5)$ & $1.1(0.8-2.2)$ & 0.098 \\
\hline - $2 \mathrm{~h}$ after fluid bolus & $1.2(0.9-1.7)$ & $1.8(1.4-8.5)$ & $1.2 *$ & 0.313 \\
\hline - $6 \mathrm{~h}$ after fluid bolus & $1.6(0.8-2.2)$ & $1.3(1-8.1)$ & $1.2^{*}$ & 0.381 \\
\hline - $24 \mathrm{~h}$ after fluid bolus & $1.1(0.8-2.6)$ & $0.9(0.8-5)$ & $0.8(0.7-1.2)$ & 0.252 \\
\hline \multicolumn{5}{|l|}{ Lactate clearance $\left(\mathrm{T}_{\mathrm{x}}-\mathrm{T}_{0}, \mathrm{mmol} / \mathrm{L}\right)$} \\
\hline - $2 \mathrm{~h}$ after fluid bolus & $-0.5(-1$ to -0.1$)$ & $-0.2(-2.5$ to +0.9$)$ & $-0.9^{*}$ & 0.979 \\
\hline - $6 \mathrm{~h}$ after fluid bolus & $-0.4(-0.8$ to -0.1$)$ & $-0.6(-3.1$ to +0.7$)$ & $-0.8^{*}$ & 0.603 \\
\hline - $24 \mathrm{~h}$ after fluid bolus & $-0.4(-1.7$ to +0.9$)$ & $-1.8(-4.6$ to -0.7$)$ & $-0.4(-1$ to +0.1$)$ & 0.084 \\
\hline \multicolumn{5}{|l|}{ Base excess (mEq/L) } \\
\hline$\cdot \mathrm{T}_{0}$ & $-5(-8.3$ to -3.7$)$ & $-5.5(-13$ to -1.8$)$ & $-3(-6.8$ to -1.5$)$ & 0.324 \\
\hline - $2 \mathrm{~h}$ after fluid bolus & $-6.8(-8.8$ to -3.2$)$ & $-2.2(-11.2$ to -0.9$)$ & $-4.9 *$ & 0.821 \\
\hline - $6 \mathrm{~h}$ after fluid bolus & $-4.6(-8.4$ to -2.5$)$ & $-0.3(-13.8$ to -0.1$)$ & $-8 *$ & 0.812 \\
\hline - $24 \mathrm{~h}$ after fluid bolus & $-2.6(-5.4$ to -0.7$)$ & $-3.2(-5.2$ to +1.7$)$ & $-4.6(-5.1$ to 0$)$ & 0.915 \\
\hline \multicolumn{5}{|l|}{ Electrolyte outcomes } \\
\hline \multicolumn{5}{|l|}{ Serum chloride level (mEq/L) } \\
\hline - $\mathrm{T}_{0}$ & $109(103.8-115)$ & $110.5(107.4-121.8)$ & $109(103.6-109.5)$ & 0.609 \\
\hline - $2 \mathrm{~h}$ after fluid bolus & $114(107.3-118)$ & $108.6(106.7-123.3)$ & $109.5 *$ & 0.755 \\
\hline - $6 \mathrm{~h}$ after fluid bolus & $112.3(108.3-116.3)$ & $110(107.8-123.2)$ & $123.5^{*}$ & 0.364 \\
\hline - $24 \mathrm{~h}$ after fluid bolus & $110.3(105.5-111.3)$ & $115(107.5-118)$ & $109.6(103.1-111.8)$ & 0.420 \\
\hline \multicolumn{5}{|l|}{ Change in chloride level $\left(\Delta\left[\mathrm{Cl}^{-}\right], \mathrm{mEq} / \mathrm{L}\right)$} \\
\hline - $2 \mathrm{~h}$ after fluid bolus & $+2(+1$ to +5$)$ & $-3.3(-0.0$ to +3.2$)$ & $+3^{*}$ & 00.200 \\
\hline - $6 \mathrm{~h}$ after fluid bolus & $+1.5(-1.4$ to +5.9$)$ & $+0.9(-1.7$ to +2.8$)$ & $+4.8 *$ & 0.393 \\
\hline - $24 \mathrm{~h}$ after fluid bolus & $+1.4(-7.1$ to +9.5$)$ & $+1.2(-9.3$ to +7.2$)$ & $+1.1(-0.6$ to +2.3$)$ & 0.963 \\
\hline \multicolumn{5}{|l|}{ Renal outcomes } \\
\hline Maximum dose of diuretics (mg//kg/24 h) & $1(0.5-1.7)$ & $1(0.4-31.5)$ & $0(0-3)$ & 0.265 \\
\hline Change in uNGAL level $(\mathrm{ng} / \mathrm{mL})$ & $-51.3(-1031$ to +0.8$)$ & $-8877.8^{*}$ & $-3.6(-34.3$ to +80.4$)$ & 0.025 \\
\hline Presence of AKI at $24 \mathrm{~h}$ after fluid bolus & $1 / 11(9.1 \%)$ & $1 / 5(20 \%)$ & $2 / 6(33.3 \%)$ & 0.461 \\
\hline \multicolumn{5}{|l|}{ PICU outcomes } \\
\hline Mechanical ventilator (d) & $4(3-15)$ & $7(3.5-11)$ & $9.5(5.3-90.8)$ & 0.720 \\
\hline Length of PICU stay (d) & $7(4-20)$ & $6(5.5-11.5)$ & $11(3.8-39)$ & 0.587 \\
\hline Length of hospital stay (d) & $24(8-72.5)$ & $27(12-117.5)$ & $31(16.3-107.3)$ & 0.973 \\
\hline Hospital mortality & $0 / 11(0 \%)$ & $1 / 5(20 \%)$ & $1 / 6(16.7 \%)$ & 0.327 \\
\hline
\end{tabular}

*sample too low, no $\mathrm{P}_{25-75}$ available from SPSS ver.22

$A K I$, Acute kidney injury; NSS, Normal saline solution; PICU, Pediatric intensive care unit; $R L S$, Ringer lactate solution; $u N G A L$, Urinary neutrophil gelatinase-associated lipocalin 
The present study did not show any difference regarding serum sodium level, chloride level, potassium level, ionized calcium level, ionized magnesium level, or change in serum chloride level $\left(\Delta\left[\mathrm{Cl}^{-}\right]\right)$at any points of measurement. No difference could be observed regarding cumulative fluid after fluid bolus therapy. Other renal outcomes also did not differ significantly among the groups. No association was found among types of fluid and abnormal coagulation study, serious bleeding, or requirement for blood product transfusion. In the present study, different types of fluid bolus therapy did not correlate with any of the PICU outcomes.

In subgroup analysis of participants who received fluid bolus therapy at large dose equal to or larger than $30 \mathrm{~mL} / \mathrm{kg}$, there was a significant decrease in urinary neutrophil gelatinase-associated lipocalin (UNGAL) level after $2 \mathrm{~h}$ of fluid bolus therapy in Ringer lactate solution (RLS) group. Other outcomes are shown in Table 1.

\section{Discussion}

Results from the present study did not show any significant different outcomes among the groups. However, the RLS group showed several potential benefits. Firstly, they had a trend towards a decrease in urinary NGAL level after $2 \mathrm{~h}$ of fluid bolus, compared to other groups. Secondly, they had a trend towards more negative $\Delta\left[\mathrm{Cl}^{-}\right]$at $2 \mathrm{~h}$. This could be explained by higher chloride content in normal saline solution (NSS) and Sterofundin, compared to RLS.

Data from the participants who received large dose of fluid bolus therapy showed a statistically significant decrease in uNGAL level at $2 \mathrm{~h}$ in the RLS group. Additionally, there was a trend towards better lactate clearance at $24 \mathrm{~h}$, and also a trend towards more negative $\Delta\left[\mathrm{Cl}^{-}\right]$at $2 \mathrm{~h}$ in this group, but not at a statistically significant level.

In general, results from the present study pointed toward the potential benefits of RLS over NSS and Sterofundin in resuscitation of children with septic shock. These findings are in line with the data from adult population $[7,8]$ and recommendations for adults with septic shock by the Surviving Sepsis Campaign in 2016 [9]. Similarly, previous retrospective studies in pediatric population with sepsis $[10,11]$ also pointed toward the same conclusion. The present study added prospective randomized, controlled trial data in this specific group of pediatric sepsis population, supported these recommendations, and made evidence slightly more solid. However, the present study had several limitations, as this was a small study, using small doses of fluid bolus, and the significant results of the present study were mostly laboratory data and biomarkers, not clinical outcomes.

\section{Conclusion}

In resuscitation of pediatric septic shock, fluid bolus therapy with any type of crystalloid solution did not result in different outcomes. However, when giving fluid bolus dose larger than $30 \mathrm{~mL} / \mathrm{kg}$, use of RLS was associated with significant uNGAL reduction.

Data Availability On request.

\section{Declarations}

Conflict of Interest None.

Source of funding This study was funded by Ratchadapiseksompotch Fund, Faculty of Medicine, Chulalongkorn University, Bangkok, Thailand, Grant number RA60/003.

\section{References}

1. Drakopoulos I, Ntetsika K, Rizos D, et al. Urinary neutrophil gelatinase-associated lipocalin (NGAL) as an early marker of acute kidney injury in critically ill multiple trauma patients. Clin Chem Lab Med. 2009;47:79-82.

2. Haase M, Bellomo R, Devarajan P, Schlattmann P, Haase-Fielitz A, NGAL Meta-analysis Investigator Group. Accuracy of neutrophil gelatinase-associated lipocalin (NGAL) in diagnosis and prognosis in acute kidney injury: a systematic review and meta-analysis. Am J Kidney Dis. 2009;54:1012-24.

3. Devarajan P. Neutrophil gelatinase-associated lipocalin: a promising biomarker for human acute kidney injury. Biomark Med. 2010;4:265-80.

4. Coca SG, Yalavarthy R, Concato J, Parikh CR. Biomarkers for the diagnosis and risk stratification of acute kidney injury: a systematic review. Kidney Int. 2008;73:1008-16.

5. Aydogdu M, Gursel G, Sancak B, et al. The use of plasma and urine neutrophil gelatinase associated lipocalin (NGAL) and cystatin $\mathrm{C}$ in early diagnosis of septic acute kidney injury in critically ill patients. Dis Markers. 2013;34:237-46.

6. Khawaja A. KDIGO clinical practice guideline for acute kidney injury. Nephron Clin Pract. 2012;120:c179-84.

7. Rochwerg B, Alhazzani W, Sindi A, et al. Fluid resuscitation in sepsis: a systematic review and network meta-analysis. Ann Intern Med. 2014;161:347-55.

8. Suetrong B, Pisitsak C, Boyd JH, Russell JA, Walley KR. Hyperchloremia and moderate increase in serum chloride are associated with acute kidney injury in severe sepsis and septic shock patients. Crit Care. 2016;20:315.

9. Rhodes A, Evans LE, Alhazzani W, et al. Surviving sepsis campaign: international guidelines for management of sepsis and septic shock: 2016. Crit Care Med. 2017;45:486-552. 
10. Stenson EK, Cvijanovich NZ, Allen GL, et al. Hyperchloremia is associated with acute kidney injury in pediatric patients with septic shock. Intensive Care Med. 2018;44:2004-5.

11. Stenson EK, Cvijanovich NZ, Anas N, et al. Hyperchloremia is associated with complicated course and mortality in pediatric patients with septic shock. Pediatr Crit Care Med. 2018;19:155-60.
Publisher's Note Springer Nature remains neutral with regard to jurisdictional claims in published maps and institutional affiliations. 